\title{
2-Chloro-2'-deoxyadenosine-induced apoptosis in T leukemia cells is mediated via a caspase-3-dependent mitochondrial feedback amplification loop
}

\author{
DAVID M. CONRAD ${ }^{1}$, MATTHEW R.J. ROBICHAUD ${ }^{2}$, JAMIE S. MADER ${ }^{3}$, ROBERT T.M. BOUDREAU ${ }^{1}$, \\ ANGELA M. RICHARDSON ${ }^{1}$, CARMAN A. GIACOMANTONIO ${ }^{2}$ and DAVID W. HOSKIN ${ }^{1,3}$ \\ Departments of ${ }^{1}$ Microbiology \& Immunology, ${ }^{2}$ Surgery and ${ }^{3}$ Pathology, Faculty of Medicine, \\ Dalhousie University, Halifax, Nova Scotia, B3H 1X5, Canada
}

Received February 1, 2008; Accepted March 19, 2008

\begin{abstract}
Chloro-2'-deoxyadenosine (CdA; cladribine) is a chemotherapeutic agent used in the treatment of certain leukemias. However, the signalling events that govern CdAmediated cytotoxicity in leukemia cells remain unclear. We show here that $\mathrm{CdA}$ treatment caused Jurkat human T leukemia cells to die via apoptosis in a dose- and time-dependent fashion. Bcl-2 overexpression protected Jurkat $\mathrm{T}$ leukemia cells from CdA-induced apoptosis and loss of mitochondrial transmembrane potential $\left(\Delta \Psi_{\mathrm{m}}\right)$. Furthermore, mitochondria that were isolated from Jurkat $\mathrm{T}$ leukemia cells and then exposed to CdA showed a loss of $\Delta \Psi_{\mathrm{m}}$, indicating that $\mathrm{CdA}$ directly compromised outer mitochondrial membrane integrity. $\mathrm{CdA}$ treatment of Jurkat $\mathrm{T}$ leukemia cells resulted in the activation of caspase- $3,-8$, and -9 , while inhibition of these caspases prevented the CdA-induced loss of $\Delta \Psi_{\mathrm{m}}$, as well as DNA fragmentation. In addition, caspase- 3 inhibition prevented caspase- 8 activation while caspase- 8 inhibition prevented caspase- 9 activation. Death receptor signalling was not involved in CdA-induced apoptosis since cytotoxicity was not affected by FADD-deficiency or antibody neutralization of either Fas ligand or tumor necrosis factor-related apoptosis-inducing ligand (TRAIL). Taken together, these data suggested that CdA-induced apoptosis in Jurkat $\mathrm{T}$ leukemia cells was mediated via a caspase-3-dependent mitochondrial feedback amplification loop. CdA treatment also increased p38 mitogen-activated protein (MAPK) and extracellular signal-regulated kinase 1 and 2 (ERK1/2) phosphorylation in Jurkat T leukemia cells. Although ERK1/2
\end{abstract}

Correspondence to: Dr David Hoskin, Department of Microbiology \& Immunology, Faculty of Medicine, Dalhousie University, Halifax, Nova Scotia, B3H 1X5, Canada

E-mail: d.w.hoskin@dal.ca

Key words: leukemia, 2-chloro-2'-deoxyadenosine, apoptosis, caspase, mitochondria, p38 mitogen-activated protein kinase inhibition did not affect CdA-mediated cytotoxicity, inhibition of p38 MAPK had an enhancing effect, which suggested a cytoprotective function for p38 MAPK. Agents that inhibit p38 MAPK might therefore increase the effectiveness of CdA-based chemotherapy.

\section{Introduction}

2-Chloro-2'-deoxyadenosine (CdA; cladribine) is a nucleoside analogue that is used in the treatment of certain haematological malignancies, including chronic lymphocytic leukemia, low-grade non-Hodgkin's lymphoma, and hairy cell leukemia $(1,2)$. CdA uptake by leukemia cells results in DNA strand breaks (3), as well as damage to mitochondria (4), both of which cause the cancer cell to die by apoptosis. Activation of the intrinsic mitochondrial pathway of apoptosis results in the release of pro-apoptotic cytochrome $c$ from mitochondria (5). Once in the cytoplasm, cytochrome $c$ forms the apoptosome complex with apoptosis protease-activating factor-1, which leads to the sequential activation of caspase- 9 and -3 . Activation of caspase-3, an 'executioner caspase', leads to DNA fragmentation, which is a central feature of apoptosis. In addition, accumulation of the 5'-triphosphate metabolite of CdA promotes mitochondria-associated apoptosis by cooperating with the apoptosome complex for the activation of caspase-3 (6). Apoptosis can also be induced via an extrinsic death receptor-triggered pathway, which is typically initiated by ligand-induced aggregation of death receptors that include Fas and tumor necrosis factor-related apoptosis-inducing ligand (TRAIL) DR4/DR5 (7). The result is activation of caspase- 8 and/or -10 , which can then directly activate caspase-3 and other effector caspases. Under certain conditions, caspase- 8 can also be activated in the absence of ligand-induced receptor aggregation $(8,9)$. However, it is important to note that the death receptor and mitochondrial pathways of apoptosis do not necessarily function in a mutually exclusive fashion (10). For example, caspase- 8 can cleave Bid, which is a member of the Bcl-2 protein family (11). The active truncated form of Bid, known as tBid, can then induce cytochrome $c$ release from mitochondria (12).

Despite several prior studies on the mechanism of CdAinduced cytotoxicity, the precise mechanism of CdA-induced 
apoptosis remains a source of controversy (13-16). Although $\mathrm{CdA}$ has been reported to kill human leukemia cells by stimulating expression of Fas and Fas ligand, thereby inducing caspase-8-dependent apoptosis (13), other studies suggest that $\mathrm{CdA}$ causes changes in mitochondrial membrane permeability that result in caspase-9-dependent apoptosis $(4,14,15)$. In addition, caspase-2, which participates in the activation of the mitochondrial pathway of apoptosis, has been implicated in CdA-induced apoptosis in astrocytoma cells (16). On the other hand, CdA-induced apoptosis in human leukemia cells has also been proposed to result from a caspase-independent process (14). Mitogen-activated protein kinases (MAPKs) have also been reported to modulate CdA-induced apoptosis. CdA treatment of EHEB B-chronic lymphocytic leukemia cells leads to the activation of extracellular signal-regulated kinase 1 and $2($ ERK1/2) while pharmacologic inhibition of ERK1/2 enhances the sensitivity of EHEB cells to killing by CdA (17). ERK1/2 activation therefore protects against CdAinduced apoptosis, at least in EHEB cells. CdA has also been shown to cause peripheral blood mononuclear cells to release interleukin-8, which is prevented by the inhibition of $\mathrm{p} 38$ MAPK (18), suggesting that p38 MAPK is activated by CdA, although the role of p38 MAPK in CdA killing of leukemia cells has not been studied.

To resolve the uncertainties that currently exist regarding the mechanism of CdA-induced cytotoxicity, we investigated the cytotoxic effect of $\mathrm{CdA}$ on human Jurkat $\mathrm{T}$ leukemia cells, with particular emphasis on the role of individual caspases, as well as MAPKs, involved in the death receptorand mitochondria-associated pathways of apoptosis. We demonstrate that in vitro treatment with CdA caused Jurkat $\mathrm{T}$ leukemia cells to die as a result of activation of the intrinsic mitochondrial pathway of apoptosis since overexpression of Bcl-2 protected Jurkat $\mathrm{T}$ leukemia cells from CdA-induced apoptosis and loss of mitochondrial transmembrane potential $\left(\Delta \Psi_{\mathrm{m}}\right)$. Moreover, CdA caused direct damage to the outer membrane of mitochondria. In addition, caspase- $3,-8$ and -9 were activated in CdA-treated Jurkat $\mathrm{T}$ leukemia cells while inhibition of these caspases prevented CdA-induced DNA fragmentation and loss of $\Delta \Psi_{\mathrm{m}}$. Furthermore, inhibition of caspase-3 prevented caspase- 8 activation and inhibition of caspase -8 prevented caspase -9 activation, implying that a caspase-3-dependent mitochondrial feedback amplification loop was involved in the cytotoxic activity of $\mathrm{CdA}$. We also found that CdA treatment of Jurkat T leukemia cells resulted in the phosphorylation of p38 MAPK and ERK1/2, but not c-jun $\mathrm{N}$-terminal kinase (JNK). Inhibition of p38 MAPK increased the killing of Jurkat $\mathrm{T}$ leukemia cells by CdA, suggesting a cytoprotective function for p38 MAPK.

\section{Materials and methods}

Cell lines. The Jurkat human T leukemia cell line was purchased from the American Type Culture Collection (Manassas, VA). Jurkat T leukemia cells engineered to overexpress Bcl-2 (19) were kindly provided by Dr R. Chris Bleackley (University of Alberta, Edmonton, Alberta, Canada). FADD-deficient $\left(\right.$ FADD $^{-/}$) Jurkat T leukemia cells (20) were a generous gift from Dr C. Hao (Emory University School of Medicine, Atlanta, GA). Cell lines were maintained in
RPMI-1640 growth medium (Sigma-Aldrich Canada Ltd., Oakville, Ontario, Canada) supplemented with 5\% heatinactivated fetal calf serum, $2 \mathrm{mM} \mathrm{L-glutamine,} 100 \mathrm{U} / \mathrm{ml}$ penicillin, $100 \mu \mathrm{g} / \mathrm{ml}$ streptomycin and $5 \mathrm{mM} \mathrm{N}$-2-hydroxyethylpiperazine-N'-2-ethanesulfonic acid (all from Invitrogen Life Technologies, Burlington, Ontario, Canada) at $37^{\circ} \mathrm{C}$ in a humidified $5 \% \mathrm{CO}_{2}$ atmosphere. Growth medium for Bcl-2overexpressing transfectants and vector-only transfectants also contained $800 \mu \mathrm{g} / \mathrm{ml} \mathrm{G} 418$ (Invitrogen).

Reagents. CdA, phenylmethylsulfonyl fluoride, leupeptin, pepstatin, aprotinin, sodium deoxycholate, 3-(4,5-dimethylthiazol-2-yl)-acetyl-2,5-diphenyltetrazolium bromide (MTT), and dimethyl sulfoxide (DMSO) were purchased from SigmaAldrich. Pan-caspase inhibitor (z-VAD-fmk), caspase-3 inhibitor (z-DEVD-fmk), caspase-8 inhibitor (z-IETD-fmk), caspase-9 inhibitor (z-LEHD-fmk), MAP ERK kinase (MEK) $1 / 2$ inhibitor (PD98059) and p38 MAPK inhibitor (SB203580) were from Calbiochem (La Jolla, CA). 3,3'-Dihexyloxacarbocyanine iodide $\left(\mathrm{DiOC}_{6}\right.$ ) was purchased from Molecular Probes (Eugene, OR) and the Annexin-V-FLUOS staining kit was purchased from Roche Diagnostics (Laval, Quebec, Canada). Tritiated-thymidine $\left(\left[{ }^{3} \mathrm{H}\right] \mathrm{TdR}\right)$ was from MP Biomedicals (Irvine, CA). Anti-Fas ligand (NOK-1) and antiTRAIL (RIK-2) neutralizing antibodies were purchased from BD Pharmingen (Mississauga, Ontario, Canada). Anti-ERK1/2 and anti-phospho-p38 antibodies were from Upstate Biotechnology (Lake Placid, NY) and Biosource International (Camarillo, CA), respectively. Mouse anti-human caspase-8 monoclonal antibody, rabbit anti-human caspase- 3 antibody, and rabbit anti-human caspase-9 antibody were from Cell Signaling Technology (Beverly, MA). Anti-phospho-ERK1/2, anti-phospho-JNK, anti-JNK, anti-p38 MAPK, anti-actin, horseradish peroxidase (HRP)-conjugated goat anti-mouseIgG, HRP-conjugated bovine anti-goat-IgG, and HRPconjugated goat anti-rabbit-IgG antibodies were obtained from Santa Cruz Biotechnology (Santa Cruz, CA).

DNA fragmentation assays. The JAM test was performed to measure DNA fragmentation (21). Jurkat T leukemia cells were labelled with $\left[{ }^{3} \mathrm{H}\right] \mathrm{TdR}(5 \mu \mathrm{Ci} / \mathrm{ml})$ for $4-6 \mathrm{~h}$. Following extensive washing, radiolabelled cells were added to quadruplicate wells $\left(5 \times 10^{4}\right.$ cells/well) of a 96-well flat-bottom microtiter plate and cultured in the absence or presence of various concentrations of $\mathrm{CdA}$ for the desired time intervals. Cells were then harvested onto glass fiber mats using a multiple sample harvester (Skatron Instruments, Sterling, VA) and $\left[{ }^{3} \mathrm{H}\right] \mathrm{TdR}$ retention was measured by scintillation counting. Percent DNA fragmentation was calculated using the following formula: $(C-E) / C \times 100$, where $C=$ counts per minute $(\mathrm{cpm})$ from control treatments, and $E=$ cpm from experimental treatments.

Alternatively, Jurkat T leukemia cells were cultured for $24 \mathrm{~h}$ in the absence or presence of $25 \mu \mathrm{M} \mathrm{CdA}$ in quadruplicate wells $\left(2.5 \times 10^{5}\right.$ cells/well $)$ of a 24 -well flat-bottom plate and DNA was harvested from cell cultures using a DNeasy ${ }^{\circledR}$ Tissue Kit according to the manufacturer's instructions (Qiagen Inc., Mississauga, Ontario, Canada). DNA samples were loaded onto a $1.5 \%$ agarose gel containing $0.5 \mathrm{mg} / \mathrm{ml}$ ethidium bromide (Sigma-Aldrich), electrophoresed in Tris-acetateEDTA buffer at $100 \mathrm{~V}$ and visualized under ultraviolet light. 
Isolation of mitochondria. Jurkat $\mathrm{T}$ leukemia cells $\left(3 \times 10^{6}\right)$ were washed twice with PBS and resuspended in $0.5 \mathrm{ml}$ mitochondrial isolation buffer (0.2 mM EDTA, $0.25 \mathrm{M}$ sucrose, $10 \mathrm{mM}$ Tris- $\mathrm{HCl}, \mathrm{pH} 7.8)$. Cells were then frozen at $-80^{\circ} \mathrm{C}$, thawed at $37^{\circ} \mathrm{C}$, and then homogenized with a pre-cooled glass homogenizer. Lysate supernatants were harvested after centrifugation at $1,000 \mathrm{~g}$ for $10 \mathrm{~min}$ at $4^{\circ} \mathrm{C}$. Mitochondria were collected from the supernatants by high-speed centrifugation $\left(12,000 \mathrm{~g}, 15 \mathrm{~min}, 4^{\circ} \mathrm{C}\right)$ and resuspended in mitochondrial isolation buffer containing protease inhibitors (1 mM DTT, $1 \mathrm{mM} \mathrm{Na} \mathrm{VO}_{4}, 1 \mathrm{mM} \mathrm{NaF}, 1 \mathrm{mM}$ phenylmethylsulfonyl fluoride, $10 \mu \mathrm{M}$ phenylarsine oxide, $1 \mu \mathrm{g} / \mathrm{ml}$ aprotinin, $1 \mu \mathrm{g} / \mathrm{ml}$ leupeptin, $1 \mu \mathrm{g} / \mathrm{ml}$ pepstatin).

Determination of $\Delta \Psi_{m}$. Flow cytometric analysis of $\mathrm{DiOC}_{6}$ stained Jurkat $\mathrm{T}$ leukemia cells was employed to determine changes in $\Delta \Psi_{\mathrm{m}}(22)$. Cells $\left(2.5 \times 10^{5}\right.$ cells $\left./ \mathrm{ml}\right)$ were cultured for $24 \mathrm{~h}$ in 24-well flat bottom plates in the absence or presence of $25 \mu \mathrm{M} \mathrm{CdA}$ with various caspase inhibitors or the DMSO vehicle control. $\mathrm{DiOC}_{6}$ was added to the cell cultures $(40 \mathrm{nM}$ final concentration) $30 \mathrm{~min}$ prior to analysis by flow cytometry.

Measurement of phosphatidylserine externalization. Jurkat $\mathrm{T}$ leukemia cells $\left(2.5 \times 10^{5}\right.$ cells $\left./ \mathrm{ml}\right)$ were cultured for $24 \mathrm{~h}$ in the absence or presence of $25 \mu \mathrm{M} \mathrm{CdA}$ in a 24-well flat bottom plate. The cells were then washed with PBS, resuspended and incubated for $15 \mathrm{~min}$ at room temperature with annexin$\mathrm{V}$-fluorescein to stain for externalized phosphatidylserine residues. After extensive washing, stained cells were analysed by flow cytometry.

Western blotting. Jurkat T leukemia cells at $5 \times 10^{5}$ cells $/ \mathrm{ml}$ were cultured for $1 \mathrm{~h}$ (for MAPK analysis) or $6 \mathrm{~h}$ (for caspase analysis) in the absence or presence of $25 \mu \mathrm{M} \mathrm{CdA}$, then pelleted by centrifugation for $5 \mathrm{~min}$ at $4^{\circ} \mathrm{C}$ and lysed with modified radioimmunoprecipitation buffer $(50 \mathrm{mM}$ Tris- $\mathrm{HCl}$, pH 7.5, $150 \mathrm{mM} \mathrm{NaCl}, 50 \mathrm{mM} \mathrm{Na} \mathrm{HPO}_{4}, 0.25 \%$ sodium deoxycholate (w/v), $0.1 \%$ Nonidet P-40 (v/v), $1 \mathrm{mM} \mathrm{Na}_{3} \mathrm{VO}_{4}$, $1 \mathrm{mM} \mathrm{NaF}, 1 \mathrm{mM}$ phenylmethylsulfonyl fluoride, $1 \mu \mathrm{g} / \mathrm{ml}$ aprotinin, $1 \mu \mathrm{g} / \mathrm{ml}$ leupeptin, $1 \mu \mathrm{g} / \mathrm{ml}$ pepstatin, $5 \mathrm{mM}$ EDTA and $5 \mathrm{mM}$ EGTA). Lysis was carried out at $4^{\circ} \mathrm{C}$ for $30 \mathrm{~min}$ and facilitated with intermittent vigorous pipetting. Cell lysates were clarified by centrifugation at $10,000 \mathrm{~g}$ for $10 \mathrm{~min}$ at $4^{\circ} \mathrm{C}$. Total protein concentration was determined for each sample by Bradford Assay (Bio-Rad, Hercules, CA) and adjusted to equivalence. Samples were then stored at $-80^{\circ} \mathrm{C}$.

Cell lysates were boiled in sodium dodecyl sulphate (SDS) sample buffer and $10 \mu \mathrm{g}$ total protein from each sample was subjected to SDS-polyacrylamide gel electrophoresis and electrotransferred onto nitrocellulose membranes. Blots were blocked with Tween-TBS buffer $(0.05 \%$ Tween-20 (v/v), $200 \mathrm{mM}$ Tris, $1.5 \mathrm{M} \mathrm{NaCl}$ ) containing $10 \%$ powdered skimmilk, and probed with the desired primary antibodies at a concentration of $1 \mu \mathrm{g} / \mathrm{ml}$ in Tween-TBS buffer containing $5 \%$ powdered skim milk. After extensive washing with Tween-TBS buffer, blots were probed with the appropriate secondary antibodies at a concentration of $1 \mu \mathrm{g} / \mathrm{ml}$ in TweenTBS buffer containing 5\% powdered skim milk, and then washed extensively with additional Tween-TBS buffer. Blots were then treated with ECL reagents (Amersham Biosciences
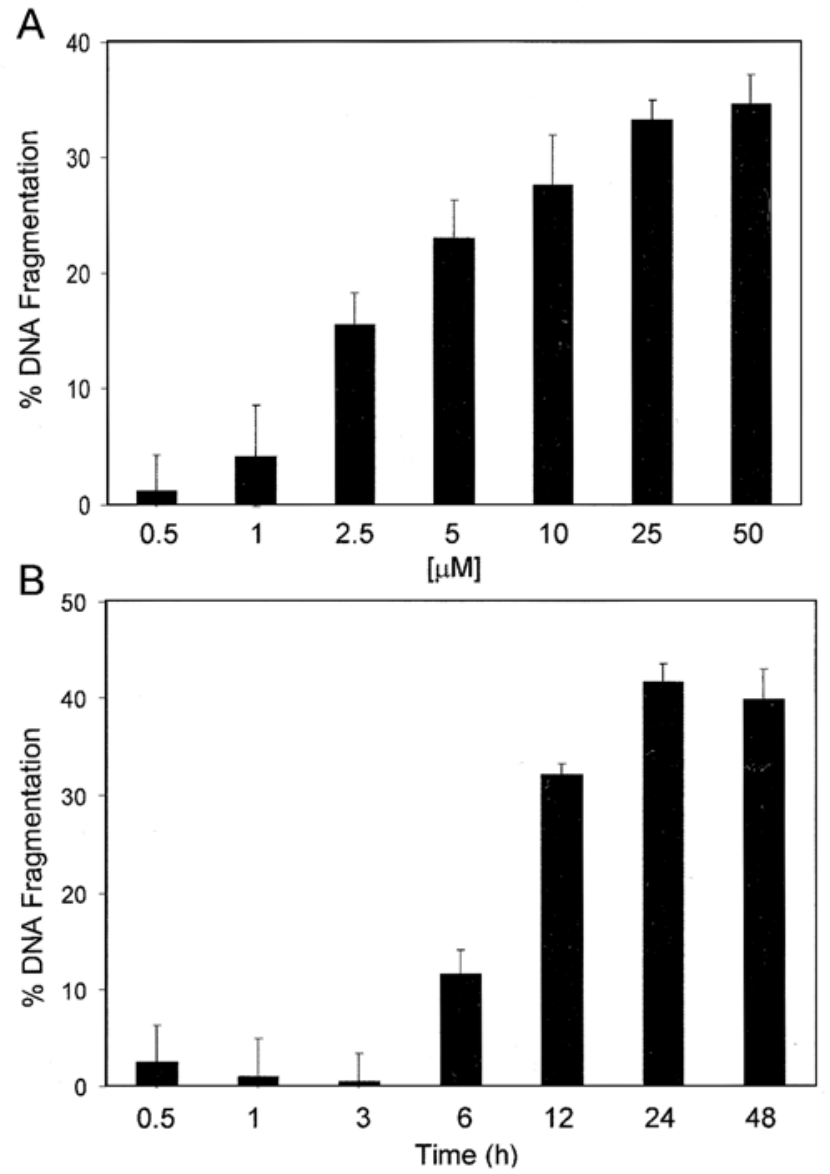

Figure 1. Dose- and time-dependent cytotoxic effect of CdA on Jurkat T leukemia cells. (A) Jurkat $\mathrm{T}$ leukemia cells were incubated for $24 \mathrm{~h}$ in the absence or presence of the indicated concentrations of CdA. (B) Jurkat T leukemia cells were incubated in the absence or presence of $25 \mu \mathrm{M} \mathrm{CdA}$ for the indicated times. (A and B) Percent DNA fragmentation was determined by JAM assay relative to control cells. Data from one representative experiment $(n=3)$ are shown as mean values \pm SD. Statistical analysis by ANOVA indicates $\mathrm{p}<0.0001$.

Inc., Baie d'Urfé, Quebec, Canada) and exposed to autoradiographic film (Amersham). Membranes were stripped by incubation for $30 \mathrm{~min}$ at $37^{\circ} \mathrm{C}$ in stripping buffer $(100 \mathrm{mM}$ ß-mercaptoethanol, $2 \%$ SDS (w/v), $62.5 \mathrm{mM}$ Tris- $\mathrm{HCl} \mathrm{pH}$ 6.7) and probed for total MAPK or actin expression as appropriate to confirm equal loading. Blocking and antibody incubations were carried out at room temperature for $1 \mathrm{~h}$, or overnight at $4^{\circ} \mathrm{C}$.

Statistical analysis. Data were analyzed using the Instat statistics program (GraphPad Software Inc., San Diego, CA). Statistical comparisons were performed using one-way analysis of variance (ANOVA) and the Bonferroni multiple comparisons test; $\mathrm{p}<0.05$ was considered to be statistically significant.

\section{Results}

Cytotoxic effect of CdA on Jurkat T leukemia cells. JAM assays, which measure DNA fragmentation (21), were used to assess the cytotoxic effect of $\mathrm{CdA}$ on Jurkat $\mathrm{T}$ leukemia cells. Fig. 1A shows that CdA treatment of Jurkat T leukemia 
cells caused DNA fragmentation to occur in a dose-dependent manner ( $<<0.0001$ by ANOVA). DNA fragmentation occurred at doses as low as $5 \mu \mathrm{M}$, and was greatest at $50 \mu \mathrm{M} \mathrm{CdA}$. Since the difference in \% DNA fragmentation induced by $25 \mu \mathrm{M} \mathrm{CdA}(33 \pm 2 \%)$ and $50 \mu \mathrm{M} \mathrm{CdA}(35 \pm 3 \%)$ was not significant $(\mathrm{p}>0.05$ by the Bonferroni multiple comparisons test), all subsequent experiments were performed using $\mathrm{CdA}$ at a final concentration of $25 \mu \mathrm{M}$. Fig. 1B shows that CdA-induced cytotoxicity was also time-dependent $(\mathrm{p}<0.0001$ by ANOVA). Jurkat cells were exposed to $25 \mu \mathrm{M} \mathrm{CdA}$, and cell death was measured by JAM assay at times ranging from $30 \mathrm{~min}$ to $48 \mathrm{~h}$. DNA fragmentation was observed as early as $6 \mathrm{~h}$ after exposure to $25 \mu \mathrm{M} \mathrm{CdA}(12 \pm 2 \%)$ and peaked after 24-h treatment $(42 \pm 2 \%)$. Maximal killing of Jurkat $\mathrm{T}$ leukemia cells after 24-h treatment with $25 \mu \mathrm{M} \mathrm{CdA}$ was confirmed by trypan-blue dye exclusion test (data not shown). We therefore chose $24 \mathrm{~h}$ as the optimal time-point at which to measure the cytotoxic effect of $25 \mu \mathrm{M} \mathrm{CdA}$ on Jurkat T leukemia cells in all subsequent experiments.

CdA induces apoptosis in Jurkat T leukemia cells. Because DNA fragmentation can be caused by necrosis, as well as apoptosis, we used gel electrophoresis to examine DNA isolated from CdA-treated Jurkat $\mathrm{T}$ leukemia cells for evidence of internucleosomal DNA cleavage, which is a hallmark of apoptosis (23). Fig. 2A shows a laddering pattern in the lane containing DNA from CdA-treated Jurkat T leukemia cells that was absent in the lane containing control DNA, indicating that internucleosomal DNA cleavage occurred in response to CdA treatment. In addition, virtually all of the control DNA had a high molecular weight, whereas the DNA from CdA-treated cells was clearly degraded. Another characteristic feature of apoptosis is externalization of phosphatidylserine, which is a membrane phospholipid normally located on the inner leaflet of the cell membrane (23). Fig. 2B shows that CdA-treated Jurkat $\mathrm{T}$ leukemia cells externalized phosphatidylserine (open peak), as indicated by a rightward shift in fluorescence due to annexin-V-fluorescein binding to cellsurface phosphatidylserine relative to the negative control (filled peak).

CdA-induced apoptosis is caspase-dependent. To determine whether caspases were activated in response to $\mathrm{CdA}$ treatment, lysates were prepared from Jurkat $\mathrm{T}$ leukemia cells following 6-h exposure to $25 \mu \mathrm{M} \mathrm{CdA}$ and analyzed by Western blotting for caspase-3, -8 , and -9 activation. Fig. 3A shows cleavage of pro-caspase- $3,-8$, and -9 in CdA-treated Jurkat T leukemia cells, indicating activation of these caspases. We next examined the role of caspases in CdA-induced apoptosis by exposing Jurkat $\mathrm{T}$ leukemia cells to a pan-caspase inhibitor (z-VADfmk) prior to and during 24-h exposure to CdA. Analysis of DNA fragmentation by JAM assay showed a near complete inhibition of CdA-induced apoptosis by z-VAD-fmk (Fig. 3B). CdA-induced apoptosis at 48- and 72-h time-points was also abrogated by $z$-VAD-fmk (data not shown), indicating that pan-caspase inhibition did not simply delay cell death and that cell death did not become caspase-independent at later time-points. Selective inhibition of caspase- 3 and -8 with z-DEVD-fmk and z-IETD-fmk, respectively, also inhibited CdA-induced DNA fragmentation, as did caspase-9 inhibition with z-LEHD-fmk, albeit to a lesser extent. These data
A
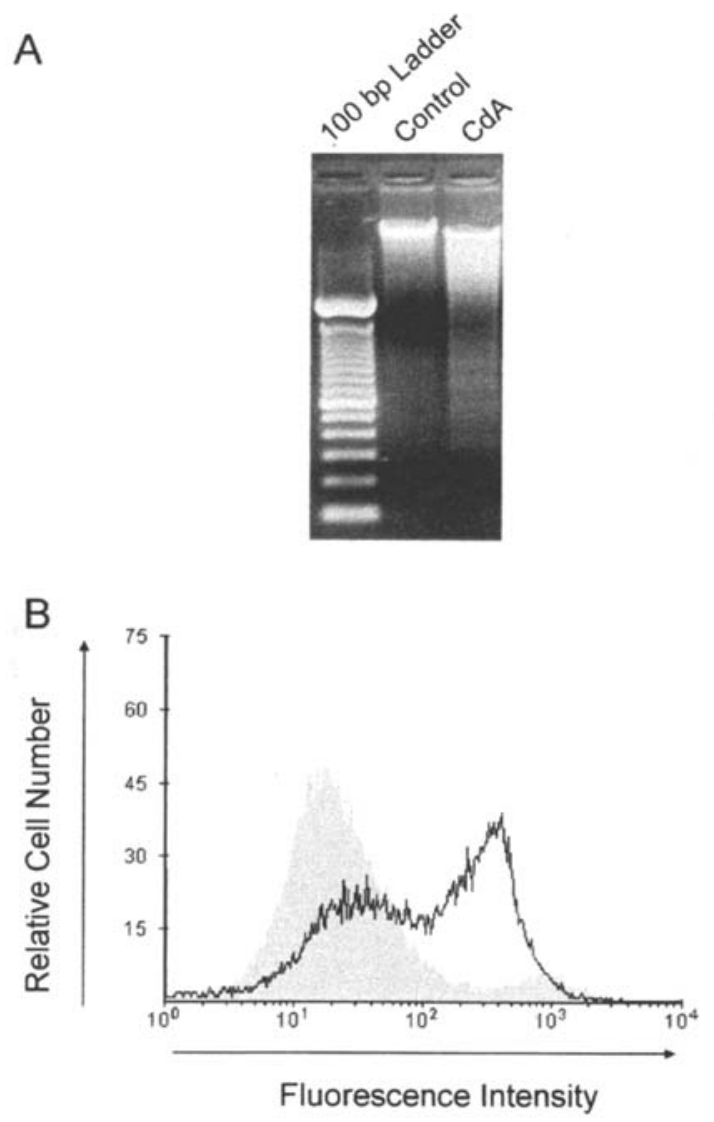

Figure 2. CdA-treated Jurkat $\mathrm{T}$ leukemia cells die by apoptosis. Jurkat $\mathrm{T}$ leukemia cells were incubated for $24 \mathrm{~h}$ in the absence or presence of $25 \mu \mathrm{M}$ CdA. (A) DNA was then isolated and resolved on an agarose gel in parallel with a 100 bp ladder. (B) FITC-annexin-V binding to CdA-treated (open peak) versus control (filled peak) cells was determined by flow cytometry. (A and B) Results are from one representative experiment $(n=3)$.

implicated caspase- $3,-8$ and -9 in the process by which CdA caused apoptosis in Jurkat $\mathrm{T}$ leukemia cells. However, caspase- 8 was not activated via a death receptor signalling pathway since $\mathrm{CdA}$ was equally cytotoxic for wild-type and FADD $^{-/}$Jurkat T leukemia cells (data not shown). Consistent with this finding, there was no decrease in CdA-induced DNA fragmentation in the presence of anti-Fas ligand or anti-TRAIL neutralizing antibodies (data not shown).

Bcl-2 protects against CdA-induced apoptosis and loss of $\Delta \Psi_{m}$. The involvement of caspase-9 in CdA killing of Jurkat T leukemia cell cultures implied activation of the mitochondrial pathway of apoptosis. Bcl-2 is an anti-apoptotic member of the $\mathrm{Bcl}-2$ protein family that regulates the intrinsic pathway of apoptosis (5). To substantiate the involvement of mitochondria in CdA-induced apoptosis, wild-type Jurkat T leukemia cells, empty vector-transfected Jurkat $\mathrm{T}$ leukemia cells, or Jurkat $\mathrm{T}$ leukemia cells that were engineered to overexpress Bcl-2 were exposed to CdA. DNA fragmentation was then measured by JAM assay. Fig. 4A shows that Bcl-2overexpressing Jurkat $\mathrm{T}$ leukemia cells were resistant to the cytotoxic effect of CdA in comparison to empty vectortransfected control cells and wild-type cells $(\mathrm{p}<0.001$ by the Bonferroni multiple comparisons test). We next used flow cytometry and $\mathrm{DiOC}_{6}$ staining to determine the effect of CdA treatment on $\Delta \Psi_{\mathrm{m}}$. Jurkat $\mathrm{T}$ leukemia cells that overexpressed 
A

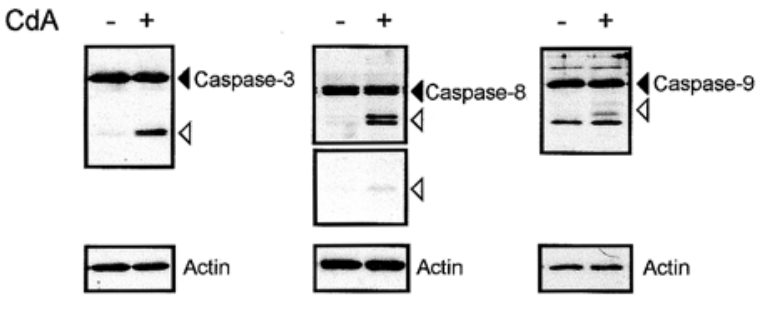

B

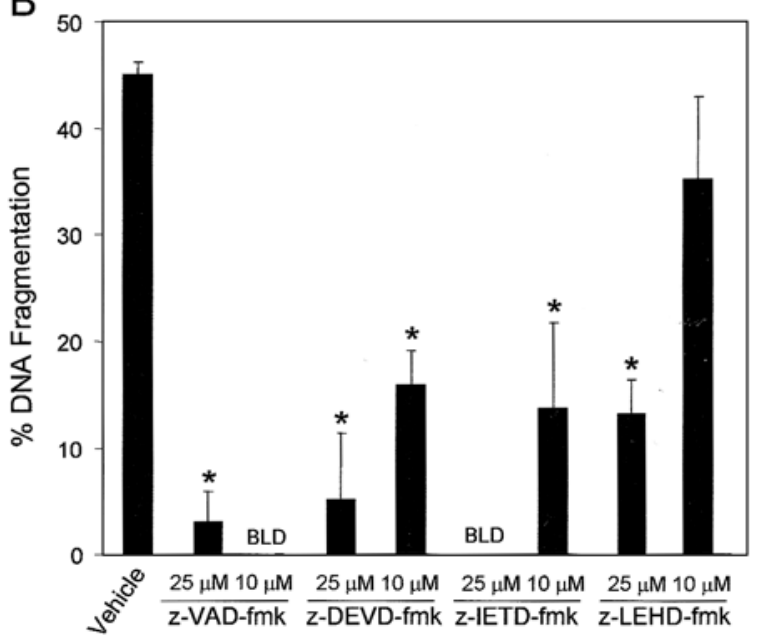

Figure 3. CdA-induced apoptosis is caspase-dependent. (A) Jurkat T leukemia cells were incubated for $6 \mathrm{~h}$ in the absence or presence of $25 \mu \mathrm{M} \mathrm{CdA}$. Cell lysates were prepared and Western blotting with anti-caspase-3, -8 , or -9 antibodies (all at $1 \mu \mathrm{g} / \mathrm{ml}$ ) was performed. Black arrowheads indicate the pro-caspase form while white arrowheads indicate major cleavage products. Blots were stripped and reprobed with antibodies against actin to confirm equal protein loading. Results are from one representative experiment $(n=3)$ (B) Jurkat T leukemia cells were treated with the drug vehicle (DMSO) alone or the indicated concentrations of z-VAD-fmk (pan-caspase inhibitor), z-DEVD-fmk (caspase-3 inhibitor), z-IETD-fmk (caspase-8 inhibitor), or z-LEHD-fmk (caspase-9 inhibitor) for $15 \mathrm{~min}$ prior to and throughout culture for $24 \mathrm{~h}$ in the presence of $25 \mu \mathrm{M}$ CdA. Percent DNA fragmentation was then measured by JAM assay. Data from one representative experiment $(n=3)$ are shown as mean values \pm SD. BLD denotes a value that was below the limit of detection. Asterisk denotes $\mathrm{p}<0.001$ by the Bonferroni multiple comparisons test relative to the vehicle control.

Bcl-2 did not show the loss of $\Delta \Psi_{\mathrm{m}}$ that control Jurkat $\mathrm{T}$ leukemia cells experienced following exposure to $\mathrm{CdA}$ (Fig. 4B), indicating that CdA treatment caused outer mitochondrial membrane integrity to be compromised. The mitochondrial membrane-permeabilizing activity of $\mathrm{CdA}$ may be directly mediated by internalized CdA since $\mathrm{DiOC}_{6}{ }^{-}$ stained mitochondria that were isolated from Jurkat $\mathrm{T}$ leukemia cells also exhibited a loss of $\Delta \Psi_{\mathrm{m}}$ following exposure to $\mathrm{CdA}$ (Fig. 5).

CdA-induced loss of $\Delta \Psi_{m}$ is caspase-dependent. Under certain conditions, the activation of caspase- 8 is a prerequisite for mitochondrial permeabilization during the apoptotic process (10). Fig. 6 shows that prior treatment of Jurkat T leukemia cells with a pan-caspase inhibitor (z-VAD-fmk), a caspase-8 inhibitor (z-IETD-fmk), or a caspase-9 inhibitor (z-LEHDfmk) prevented the subsequent loss of $\Delta \Psi_{\mathrm{m}}$ in response to $\mathrm{CdA}$ treatment, as determined by flow cytometric analysis of DiOC $_{6}$-stained cells. Treatment with a caspase-3 inhibitor

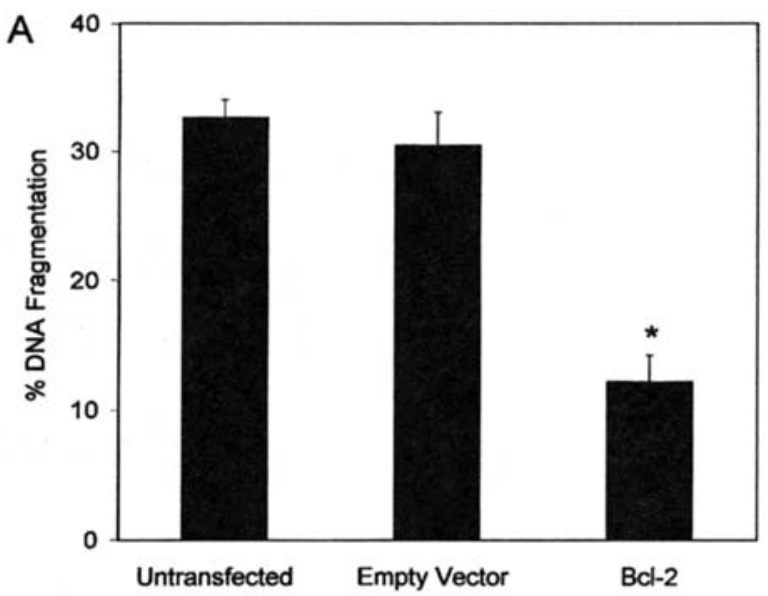

B

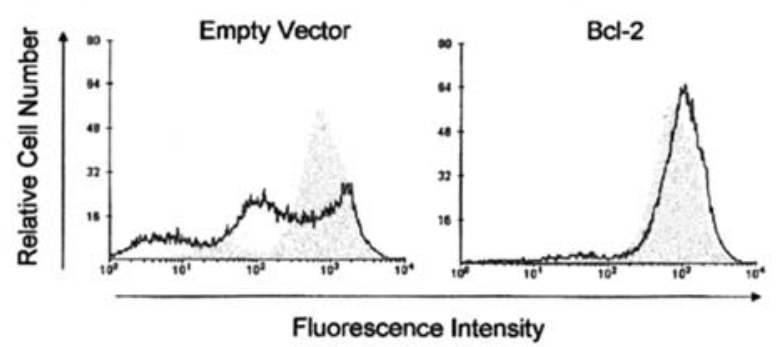

Figure 4. Bcl-2 overexpression protects Jurkat T leukemia cells from CdAinduced apoptosis and prevents loss of $\Delta \Psi_{\mathrm{m}}$. (A) Wild-type Jurkat T leukemia cells or Jurkat $\mathrm{T}$ leukemia cells transfected with an empty vector or the $\mathrm{Bcl}-2$ gene were cultured for $24 \mathrm{~h}$ in the absence or presence of $25 \mu \mathrm{M} \mathrm{CdA}$. Percent DNA fragmentation was then determined by JAM assay. Data from one representative experiment $(n=3)$ are shown as mean values \pm SD. Asterisk denotes $\mathrm{p}<0.001$ by the Bonferroni multiple comparisons test relative to the wild-type and empty vector controls. (B) Jurkat T leukemia cells transfected with an empty vector or the Bcl-2 gene were cultured for $24 \mathrm{~h}$ in the absence or presence of $25 \mu \mathrm{M}$ CdA. Cells were loaded with $40 \mathrm{nM}$ $\mathrm{DiOC}_{6} 30 \mathrm{~min}$ prior to the end of the assay, and $\Delta \Psi_{\mathrm{m}}$ was measured by flow cytometry. Loss of $\Delta \Psi_{\mathrm{m}}$ is indicated by a leftward shift in fluorescence. Filled peaks indicate control cells while open peaks indicate cells treated with CdA. Data are from one representative experiment $(n=3)$.

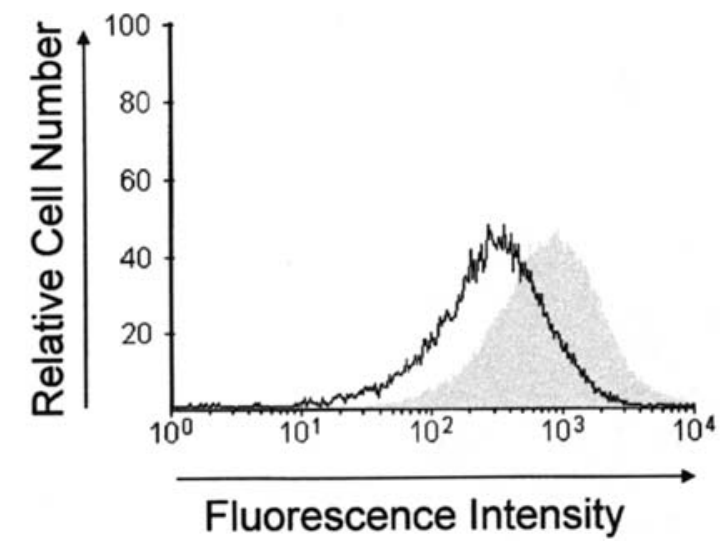

Figure 5. CdA causes direct damage to the outer mitochondrial membrane. Mitochondria were isolated from Jurkat T leukemia cells as described in Materials and methods, exposed to $25 \mu \mathrm{M} \mathrm{CdA}$ for $30 \mathrm{~min}$, and then loaded with $40 \mathrm{nM} \mathrm{DiOC}_{6}$. After $30 \mathrm{~min}, \Delta \Psi_{\mathrm{m}}$ was measured by flow cytometry. Loss of $\Delta \Psi_{\mathrm{m}}$ is indicated by a leftward shift in fluorescence. The filled peak indicates control mitochondria while the open peak indicates mitochondria treated with CdA. Data are from one representative experiment $(n=3)$. 


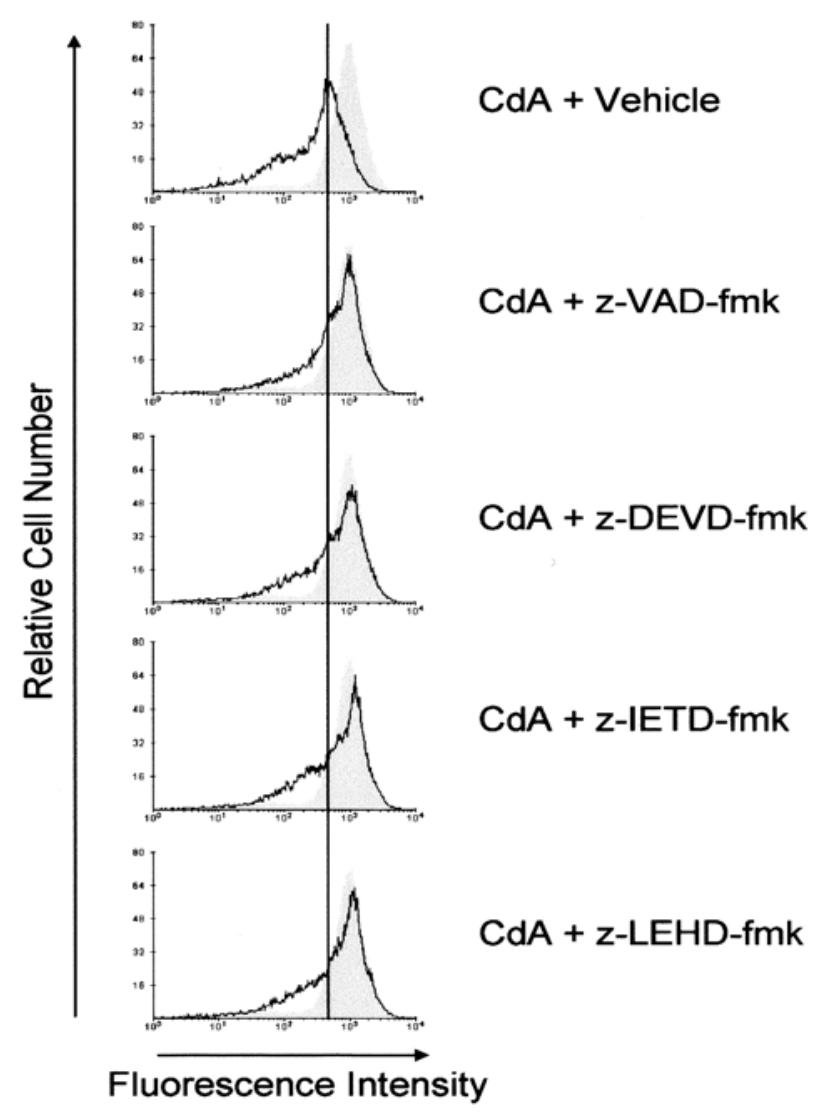

Figure 6. CdA causes a caspase-dependent loss of $\Delta \Psi_{\mathrm{m}}$ Jurkat T leukemia cells were exposed to the drug vehicle (DMSO) alone or to $25 \mu \mathrm{M} \mathrm{z}$-VAD-fmk (pan-caspase inhibitor), z-DEVD-fmk (caspase-3 inhibitor), z-IETD-fmk (caspase-8 inhibitor), or z-LEHD-fmk (caspase-9 inhibitor) for $15 \mathrm{~min}$ prior to and during culture for $24 \mathrm{~h}$ in the presence of $25 \mu \mathrm{M} \mathrm{CdA}$. Cells were loaded with $40 \mathrm{nM} \mathrm{DiOC}_{6} 30$ min prior to the end of the assay and flow cytometry was used to compare changes in $\Delta \Psi_{\mathrm{m}}$ between the different treatment groups. Loss of $\Delta \Psi_{\mathrm{m}}$ is indicated by a leftward shift in fluorescence. Filled peaks indicate control cells while open peaks indicate cells treated with $\mathrm{CdA}$ plus caspase inhibitors or the DMSO vehicle. Results are from one representative experiment $(n=3)$

(z-DEVD-fmk) before and during CdA treatment of Jurkat T leukemia cells also prevented the subsequent loss of $\Delta \Psi_{\mathrm{m}}$. These findings suggested that caspase- $3,-8$ and -9 contributed to mitochondrial membrane disruption in CdA-treated Jurkat $\mathrm{T}$ leukemia cells.

CdA induction of a caspase-3-dependent mitochondrial feedback amplification loop. Processing of caspase-9, -3 , and -8 following the release of cytochrome $c$ from mitochondria into the cytosolic compartment has previously been associated with CdA treatment of leukemia cells (24), although potential interactions between these caspases was not examined. Since caspase- 8 can contribute to mitochondrial permeabilization (10), we determined whether caspase-3 activation promoted caspase- 8 activation, which in turn might enhance caspase- 9 activation in CdA-treated Jurkat $\mathrm{T}$ leukemia cells. Fig. 7 shows that caspase- 8 activation following CdA treatment of Jurkat $\mathrm{T}$ leukemia cells was largely prevented in the presence of z-DEVD-fmk (caspase-3 inhibitor), indicating caspase-3dependent activation of caspase-8. Furthermore, caspase- 9 activation was substantially reduced in the presence of z-IETDfmk (caspase- 8 inhibitor), suggesting that caspase- 8 amplified

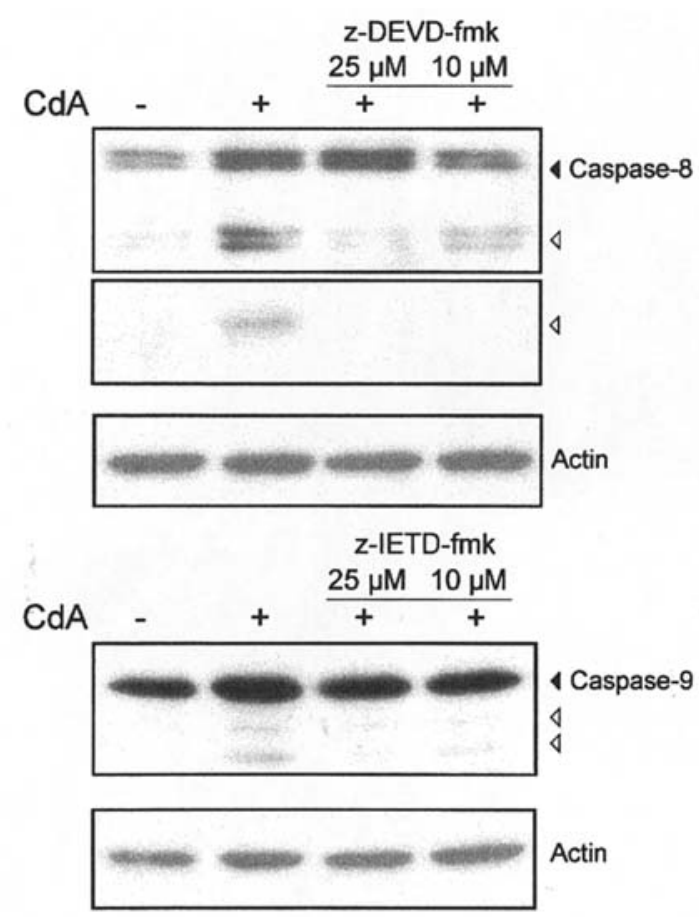

Figure 7. Caspase-3-dependent activation of caspase- 8 and caspase-8dependent activation of caspase- 9 following CdA treatment. Jurkat T leukemia cells were cultured for $6 \mathrm{~h}$ in the absence or presence of $25 \mu \mathrm{M} \mathrm{CdA}$ without or with z-DEVD-fmk (caspase-3 inhibitor) or z-IETD-fmk (caspase-8 inhibitor) at the indicated concentrations. Cell lysates were prepared and Western blotting with anti-caspase- 8 or -9 antibodies (both at $1 \mu \mathrm{g} / \mathrm{ml}$ ) was performed. Black arrowheads indicate the pro-caspase form while white arrowheads indicate major cleavage products. Blots were stripped and reprobed with antibodies against actin to confirm equal protein loading. Results are from one representative experiment $(n=3)$.

the activity of caspase-9. Taken together, these data are consistent with the sequential activation of caspase-9, -3 , and -8 leading to additional caspase- 9 activation, i.e., initiation of a mitochondrial feedback amplification loop, that enhanced CdA-induced apoptosis in Jurkat T leukemia cells.

p38 MAPK activation protects against CdA-induced apoptosis. Since MAPKs have been implicated in CdA-induced intracellular signalling in other cell types $(17,18)$, we employed Western blotting and antibodies against phospho-ERK1/2, phospho-p38 MAPK, and phospho-JNK to determine levels of activated ERK1/2, p38 MAPK, and JNK in lysates from control and CdA-treated Jurkat T leukemia cells. Fig. 8A shows that CdA treatment caused a substantial increase in p38 MAPK phosphorylation, as well as a more modest increase in ERK1/2 phosphorylation. No detectable increase in JNK phosphorylation was observed in response to CdA treatment. To determine whether ERK1/2 and/or p38 MAPK activation affected CdA-induced cytotoxicity, Jurkat T leukemia cells were treated with PD98059 (a MEK inhibitor that inhibits ERK1/2 activation) or SB203580 (a p38 MAPK inhibitor) before and throughout $\mathrm{CdA}$ treatment. Fig. $8 \mathrm{~B}$ shows that inhibition of ERK1/2 did not protect against CdA-induced apoptosis, whereas inhibition of p38 MAPK resulted in a significant increase $(\mathrm{p}<0.001$ by the Bonferroni multiple comparisons test) in CdA-induced DNA fragmentation, suggesting that p38 MAPK opposed CdA killing of Jurkat 


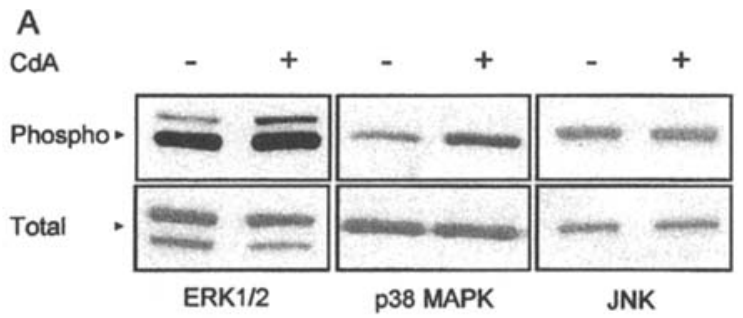

B

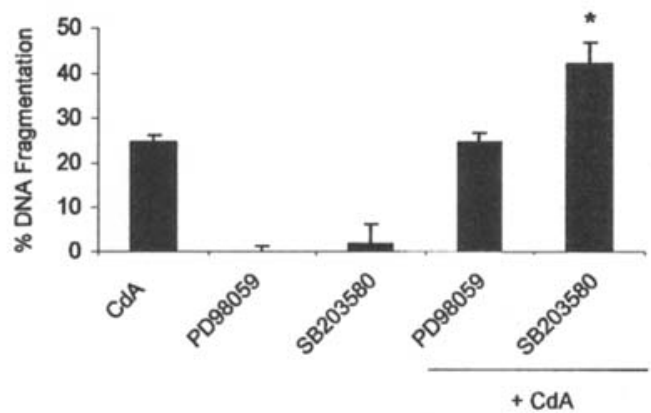

Figure 8. CdA treatment of Jurkat T leukemia cells causes p38 MAPK activation that interferes with drug cytotoxicity. (A) Jurkat T leukemia cells were cultured for $1 \mathrm{~h}$ in the absence or presence of $25 \mu \mathrm{M} \mathrm{CdA}$. Cell lysates were prepared and Western blotting with antibodies specific for phosphoERK 1/2, phospho-p38 MAPK, and phospho-JNK (all $1 \mu \mathrm{g} / \mathrm{ml}$ ) was performed to detect activation-specific ERK1/2, p38 MAPK and JNK phosphorylation. Blots were stripped and reprobed with antibodies specific for ERK1/2, p38 MAPK and JNK to confirm equal protein loading. Results are from one representative experiment $(n=3)(B)$ Jurkat T leukemia cells were exposed to the drug vehicle (DMSO) alone or to $10 \mu \mathrm{M}$ PD98059 (a MEK1/2 inhibitor that prevents ERK1/2 activation) or $10 \mu \mathrm{M} \mathrm{SB} 203580$ (a p38 MAPK inhibitor) for 15 min prior to and throughout culture for $24 \mathrm{~h}$ in the presence of $25 \mu \mathrm{M} \mathrm{CdA}$. Percent DNA fragmentation was then determined by JAM assay. Data from one representative experiment $(n=3)$ are shown as mean values \pm SD. Asterisk denotes $\mathrm{p}<0.001$ in comparison to cells treated with CdA alone by the Bonferonni multiple comparisons test.

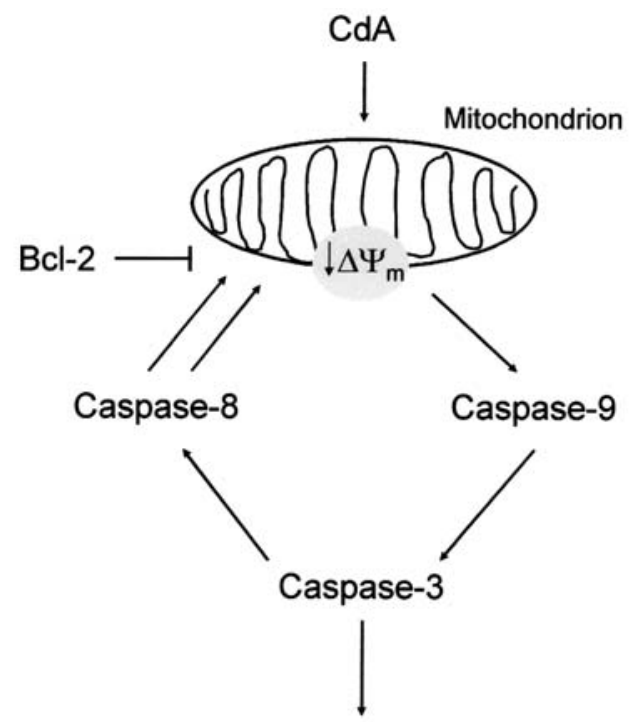

p38 MAPK — APOPTOSIS

Figure 9. Model of CdA-induced apoptosis in Jurkat T leukemia cells. CdA causes direct damage to the mitochondrial outer membrane, resulting in the sequential activation of caspase-9, -3 , and -8 , which creates a Bcl-2-regulated mitochondrial feedback amplification loop that results in further loss of $\Delta \Psi_{\mathrm{m}}$ and processing of caspases. Activation of p38 MAPK opposes CdA-induced apoptosis at a level downstream of mitochondrial permeabilization and caspase activation.
T leukemia cells. Interestingly, p38 MAPK inhibition did not substantially affect the loss of $\Delta \Psi_{\mathrm{m}}$ caused by CdA treatment (data not shown).

\section{Discussion}

CdA has been reported to induce apoptosis in various human leukemia and lymphoma cell lines, including MOLT-4 T-acute lymphoblastic leukemia cells (13) and U937 promonocytic leukemia cells (14), as well as primary B-chronic lymphoblastic leukemia cells (15). Despite intensive study, the precise mechanism of CdA-induced apoptosis remains controversial. In particular, the role of individual caspases in CdA-induced apoptosis remains a major point of contention within the existing literature. Here, we show that exposure to $\mathrm{CdA}$ caused Jurkat $\mathrm{T}$ leukemia cells to die by caspase-dependent apoptosis because $\mathrm{CdA}$ treatment resulted in the activation of caspase-3, -8 , and -9 while a general caspase inhibitor (z-VAD-fmk) virtually abrogated the ability of CdA to induce DNA fragmentation. Moreover, z-VAD-fmk did not simply delay cell death nor was cell death caspase-independent at later time-points since z-VAD-fmk-treated Jurkat T leukemia cells remained viable after 72-h culture in the presence of $\mathrm{CdA}$. In addition, CdA-induced apoptosis was potently inhibited by selective inhibitors of caspase- 8 (z-IETD-fmk) and caspase-3 (z-DEVD-fmk), while a selective inhibitor of caspase-9 (z-LEHD-fmk) had a less dramatic but still substantial inhibitory effect. Our findings are therefore consistent with previous reports that caspase- $3,-8$, and/or -9 are activated following CdA treatment of several different leukemic cell lines $(13,14,24)$. Although Marzo and colleagues (14) concluded that CdA-induced apoptosis in human leukemic cell lines is mediated through both caspase-dependent and -independent pathways, our findings argue against a major role for caspase-independent apoptosis in the cytotoxic effect of CdA on Jurkat T leukemia cells.

Caspase- 8 is typically activated in response to the ligation of death receptors such as Fas or TRAIL DR4/DR5 by Fas ligand and TRAIL, respectively (7). CdA has previously been shown to cause Fas and Fas ligand expression to be up-regulated in MOLT-4 human T leukemia cells, implying that $\mathrm{CdA}$ induces a death receptor-mediated form of apoptosis (13). Moreover, apoptosis that is induced in human lymphocytes by another nucleoside analogue, 9-3-D-arabinofuranosyl2-fluoroadenine (fludarabine), is associated with up-regulated Fas and Fas ligand expression and is also impaired by antibodymediated neutralization of Fas or Fas ligand (25). However, we found that $\mathrm{FADD}^{-/}$Jurkat T leukemia cells and their wild-type counterparts were equally sensitive to CdA-induced cytotoxicity. In addition, neutralizing antibodies against Fas ligand or TRAIL did not prevent DNA fragmentation in CdA-treated Jurkat T leukemia cells. CdA killing of Jurkat T leukemia cells was therefore not initiated by ligand-induced death receptor signalling. This finding is consistent with a recent report that anti-Fas neutralizing antibody fails to interfere with CdA-induced apoptosis in leukemia cells (24). It is important to note that the involvement of caspase- 8 in an apoptotic pathway does not necessarily imply death receptor involvement since anticancer drugs can induce caspase- 8 activation and apoptosis via a mechanism that is independent of death receptor ligands $(8,9)$. Indeed, caspase- 8 
activation has been shown to occur in paclitaxel-treated lymphoma cells that express a dominant-negative form of FADD and are therefore unable to initiate Fas death receptor signalling (26). In view of our evidence that caspase- 8 plays an important role in mediating CdA-induced apoptosis in Jurkat $\mathrm{T}$ leukemia cells, it is puzzling that Klöpfer and colleagues (24) were unable to demonstrate any reduction in CdA-induced DNA fragmentation in mutant leukemia cells that lacked caspase-8. One possible explanation is that $\mathrm{CdA}$ treatment also results in the caspase-3-mediated activation of initiator caspase-10, which has previously been demonstrated in a cell-free system (27). Interestingly, caspase-10 has recently been shown to be involved in a mitochondrial feedback amplification loop that enhances caspase-9 and -3 activation following etoposide treatment of U937 promonocytic leukemia cells (28).

The mitochondrial pathway of apoptosis is regulated by members of the Bcl-2 protein family, including Bcl-2 and Bax (5). Bcl-2 opposes the action of Bax, which, in response to an apoptotic signal, translocates from the cytoplasm to the mitochondrion where it initiates mitochondrial membrane permeabilization. In line with this, we observed that Jurkat $\mathrm{T}$ leukemia cells that were engineered to overexpress Bcl-2 were significantly less sensitive to CdA than wild-type cells or control cells transfected with an empty vector, suggesting that the mitochondrion played a central role in $\mathrm{CdA}$-induced apoptosis. Moreover, overexpression of $\mathrm{Bcl}-2$ prevented the loss of $\Delta \Psi_{\mathrm{m}}$ that was observed in CdA-treated Jurkat $\mathrm{T}$ leukemia cells. In addition, preparations of mitochondria isolated from Jurkat $\mathrm{T}$ leukemia cells also exhibited loss of $\Delta \Psi_{\mathrm{m}}$ following CdA treatment, which was consistent with a direct permeabilizing effect by $\mathrm{CdA}$ on the outer membrane of mitochondria. Interestingly, a recent study shows that CdA-induced cleavage of pro-caspase- 8 into its active form is delayed in Bcl-2-transfected leukemia cells, suggesting that caspase- 8 is processed downstream of mitochondrial pore formation in response to CdA treatment (24). Our data indicate that caspase- $3,-8$, and -9 contributed to the loss of mitochondrial outer membrane integrity in CdA-treated Jurkat T leukemia cells since the CdA-induced loss of $\Delta \Psi_{\mathrm{m}}$ was prevented in the presence of z-VAD-fmk, as well as selective inhibitors of caspase- $3,-8$, and -9 . This finding is consistent with the suggestion that CdA-induced apoptosis in leukemia cells involves the sequential processing of caspase-9, -3 , and -8 following the release of cytochrome $c$ from mitochondria into the cytosolic compartment (24).

In our hands, inhibition of caspase-3 with z-DEVD-fmk prevented CdA-induced activation of caspase- 8 while inhibition of caspase- 8 with IETD-fmk substantially reduced caspase-9 activation in CdA-treated Jurkat T leukemia cells, suggesting that CdA-induced apoptosis was mediated via a caspase-3dependent mitochondrial feedback amplification loop, as depicted in Fig. 9. In this scheme, nucleoside-induced damage to the outer membrane of mitochondria causes the initial release of sufficient cytochrome $c$ to initiate low level sequential activation of caspase- 9 and -3 . Caspase- 8 is then activated via caspase-3, which leads to further permeabilization of the outer membrane of mitochondria with the attendant release of additional cytochrome $c$, apoptosome formation, and further feedback amplification of the apoptotic response. Caspase- 8 processing of cytoplasmic Bid is likely to be a prerequisite for mitochondrial membrane permeabilization at this point in the amplification loop (12), which is regulated by Bcl-2, thereby accounting for the inhibitory effect of $\mathrm{Bcl}-2$ overexpression. Interestingly, paclitaxel-induced apoptosis in B lymphoma cells has recently been suggested to result from a similar mitochondrial amplification loop driven by caspase-3 and -8 (26). CdA may also promote the loss of mitochondrial membrane integrity by altering the balance between pro- and antiapoptotic Bcl-2 family members since $\mathrm{Bcl}-2$ expression is decreased in malignant cells of CdA-treated patients with Bchronic lymphoblastic leukemia (29).

The MAPK family of signalling proteins regulate a myriad of biological processes that include cell proliferation, differentiation, and apoptosis (30). ERK1/2, p38 MAPK and JNK are MAPKs that have been implicated in the response of cancer cells to various chemotherapeutic agents (31). ERK1/2 signalling is usually protective $(32,33)$ whereas JNK and p38 MAPK activation usually promote cancer cell death (33-35). ERK1/2 is activated following CdA treatment of B cell-derived EHEB leukemia cells while inhibition of ERK1/2 increases the sensitivity of EHEB leukemia cells to CdA-mediated cytotoxicity (17), suggesting that ERK1/2 activation might guard against CdA-induced cytotoxicity. However, inhibition of ERK1/2 with the MEK inhibitor PD98059 did not affect CdA-induced DNA fragmentation in Jurkat $\mathrm{T}$ leukemia cells, even though a modest increase in ERK1/2 phosphorylation was observed following CdA treatment. The cytoprotective function of CdA-elicited ERK1/2 activation therefore appears to be restricted to certain cancer cell types. Although JNK was not activated in CdA-treated Jurkat T leukemia cells, we observed a substantial increase in p38 MAPK phosphorylation in these cells. Interestingly, inhibition of p38 MAPK signalling with SB203580 caused increased DNA fragmentation in response to CdA treatment but did not prevent the loss of $\Delta \Psi_{\mathrm{m}}$, suggesting that Jurkat T leukemia cells were protected from CdA-induced cytotoxicity by p38 MAPK activation that occurred downstream of caspase activation (Fig. 9). This observation was in sharp contrast to the generally accepted belief that p38 MAPK plays a pro-apoptotic role in cancer cells treated with chemotherapeutic agents (36). However, there is emerging evidence that p38 MAPK can, under some circumstances, function as a survival factor for cancer cells. For example, inhibition of p38 MAPK sensitizes retinoblastoma cells to ultraviolet radiation (37) and breast carcinoma cells to death receptor-induced apoptosis (38). Activation of NF-кB in response to p38 MAPK signalling (39) might account for the survival-promoting role of p38 MAPK in certain cancer cells $(37,38)$. Our own findings indicate that pharmacological or molecular inhibition of p38 MAPK signalling warrants further investigation as a possible approach to increasing the effectiveness of $\mathrm{CdA}$ in the treatment of haematological malignancies.

\section{Acknowledgments}

This work was supported by a grant from the Natural Sciences and Engineering Research Council (NSERC) of Canada to D. Hoskin. D. Conrad was the recipient of an NSERC Postgraduate Scholarship and a Nova Scotia Health Research Foundation (NSHRF) Studentship. J. Mader and R. Boudreau 
were recipients of NSHRF Studentships. A. Richardson was supported by a Cancer Research Training Program Studentship with funding from the Canadian Cancer Society and the Dalhousie Cancer Research Program.

\section{References}

1. Johnson SA: Nucleoside analogues in the treatment of haematological malignancies. Expert Opin Pharmacother 2: 929-943, 2001.

2. Goodman GR, Bethel KJ and Saven A: Hairy cell leukemia: an update. Curr Opin Hematol 10: 258-266, 2003.

3. Carson DA, Carrera CJ, Wasson DB and Yamanaka H: Programmed cell death and deoxynucleotide metabolism in human lymphocytes. Adv Enzyme Regul 27: 395-404, 1988.

4. Genini D, Adachi S, Chao Q, Rose DW, Carrera CJ, Cottam HB, Carson DA and Leoni LM: Deoxyadenosine analogs induce programmed cell death in chronic lymphocytic leukemia cells by damaging the DNA and by directly affecting the mitochondria. Blood 96: 3537-3543, 2000 .

5. Green DR and Reed JC: Mitochondria and apoptosis. Science 281: 1309-1312, 1998 .

6. Leoni LM, Chao Q, Cottam HB, Genini D, Rosenbach M, Carrera CJ, Budihardjo I, Wang X and Carson DA: Induction of an apoptotic program in cell-free extracts by 2-chloro-2'-deoxyadenosine 5'-triphosphate and cytochrome c. Proc Natl Acad Sci USA 95: 9567-9571, 1998 .

7. Ashkenazi A and Dixit VM: Death receptors: signaling and modulation. Science 284: 1305-1308, 1998.

8. Wesselborg S, Engels IH, Rossmann E, Los M and SchulzeOsthoff K: Anticancer drugs induce caspase-8/FLICE activation and apoptosis in the absence of CD95 receptor/ligand interaction. Blood 93: 3053-3063, 1999.

9. Sohn D, Schulze-Osthoff K and Janicke RU: Caspase-8 can be activated by interchain proteolysis without receptor-triggered dimerization during drug-induced apoptosis. J Biol Chem 280: 5267-5273, 2005

10. Scaffidi C, Fulda S, Srinivasan A, Friesen C, Li F, Tomaselli KJ, Debatin KM, Krammer PH and Peter ME: Two CD95 (APO1/Fas) signaling pathways. EMBO J 17: 1675-1687, 1998.

11. Li H, Zhu H, Xu CJ and Yuan J: Cleavage of BID by caspase 8 mediates the mitochondrial damage in the Fas pathway of apoptosis. Cell 94: 491-501, 1998.

12. Luo X, Budihardjo I, Zou H, Slaughter C and Wang X: Bid, a $\mathrm{Bcl} 2$ interacting protein, mediates cytochrome c release from mitochondria in response to activation of cell surface death receptors. Cell 94: 481-490, 1998

13. Nomura Y, Inanami O, Takahashi K, Matsuda A and Kuwabara M: Cladribine induces apoptosis through the Fas/Fas ligand pathway in human leukemia cell line MOLT-4. Leukemia 14: 299-306, 2000.

14. Marzo I, Perez-Galan P, Giraldo P, Rubio-Felix D, Anel A and Naval J: Cladribine induces apoptosis in human leukaemia cells by caspase-dependent and -independent pathways acting on mitochondria. Biochem J 359: 537-546, 2001.

15. Perez-Galan P, Marzo I, Giraldo P, Rubio-Felix D, Lasierra P, Larrad L, Anel A and Naval J: Role of caspases and apoptosisinducing factor (AIF) in cladribine-induced apoptosis of B cell chronic lymphocytic leukemia. Leukemia 16: 2106-1214, 2002.

16. Ceruti S, Beltrami E, Matarrese P, Mazzola A, Cattabeni F, Malorni W and Abbracchio MP: A key role for caspase-2 and caspase- 3 in the apoptosis induced by 2-chloro-2'-deoxy-adenosine (cladribine) and 2-chloro-adenosine in human astrocytoma cells. Mol Pharmacol 63: 1437-1447, 2003.

17. Smal C, Lisart S, Maerevoet M, Ferrant A, Bontemps F and van Den Nest E: Pharmacological inhibition of the MAPK/ERK pathway increases sensitivity to 2-chloro-2'-deoxyadenosine $(\mathrm{CdA})$ in the B-cell leukemia cell line EHEB. Biochem Pharmacol 73: 351-358, 2007

18. Mühl H, Nold M, Chang JH, Frank S, Eberhardt W and Pfeilschifter J: Expression and release of chemokines associated with apoptotic cell death in human promonocytic U937 cells and peripheral blood mononuclear cells. Eur J Immunol 29: 3225-3235, 1999.

19. Heibein JA, Goping IS, Barry M, Pinkowski MJ, Shore GC, Green DR and Bleackley RC: Granzyme B-mediated cytochrome $\mathrm{c}$ release is regulated by the $\mathrm{Bcl}-2$ family members Bid and Bax. J Exp Med 192: 1391-1402, 2000.
20. Juo P, Woo MS, Kuo CJ, Signorelli P, Biemann HP, Hannun YA and Blenis J: FADD is required for multiple signaling events downstream of the receptor Fas. Cell Growth Differ 10: 797-804, 1999

21. Matzinger P: The JAM test. A simple assay for DNA fragmentation and cell death. J Immunol Methods 145: 185-192, 1991.

22. Levenson R, Macara IG, Smith RL, Cantley L and Housman D: Role of mitochondrial membrane potential in the regulation of murine erythroleukemia cell differentiation. Cell 28: 855-863, 1982.

23. Fleisher TA: Apoptosis. Ann Allergy Asthma Immunol 78: 245-249, 1997.

24. Klöpfer A, Hasenjäger A, Belka C, Schulze-Osthoff K, Dörken B and Daniel PT: Adenine deoxynucleotides fludarabine and cladribine induce apoptosis in a CD95/Fas receptor, FADD and caspase-8-independent manner by activation of the mitochondrial cell death pathway. Oncogene 23: 9408-9418, 2004.

25. Rao VA and Plunkett W: Activation of a p53-mediated apoptotic pathway in quiescent lymphocytes after the inhibition of DNA repair by fludarabine. Clin Cancer Res 9: 3204-3212, 2003.

26. Von Haefen C, Wieder T, Essmann F, Schulze-Osthoff K, Dorken B and Daniel PT: Paclitaxel-induced apoptosis in BJAB cells proceeds via a death receptor-independent, caspases-3/-8 driven mitochondrial amplification loop. Oncogene 22: 2236-2247, 2003.

27. Yang S, Thor AD, Edgerton S and Yang X: Caspase-3 mediated feedback activation of apical caspases in doxorubicin and TNF- $\alpha$ induced apoptosis. Apoptosis 11: 1987-1997, 2006.

28. Filomenko R, Prévotat L, Rébé C, Cortier M, Jeannin JF, Solary E and Bettaieb A: Caspase-10 involvement in cytotoxic drug-induced apoptosis of tumor cells. Oncogene 25: 7635-7645, 2006.

29. Rogalinska M, Blonski JZ, Hanausek M, Walaszek Z, Robak T and Kilianska ZM: 2-Chlorodeoxyadenosine alone and in combination with cyclophosphamide and mitoxantrone induce apoptosis in B chronic lymphocytic leukemia in vivo. Cancer Detect Prev 28: 433-442, 2004

30. Platanians LC: MAP kinase signaling pathways and hematologic malignancies. Blood 101: 4667-4679, 2003.

31. Fan M and Chambers TC: Role of mitogen-activated protein kinases in the response of tumor cells to chemotherapy. Drug Resist Updat 5: 253-267, 2001.

32. Persons DL, Yazlovitskaya EM, Cui W and Pelling JC: Cisplatininduced activation of mitogen-activated protein kinases in ovarian carcinoma cells: inhibition of extracellular signal-regulated kinase activity increases sensitivity to cisplatin. Clin Cancer Res 5: 1007-1014, 1999

33. Bacus SS, Gudkov AV, Lowe M, Lyass L, Yung Y, Komarov AP, Keyomarsi K, Yarden Y and Seger R: Taxol-induced apoptosis depends on MAP kinase pathways (ERK and p38) and is independent of p53. Oncogene 20: 147-155, 2001.

34. Fan M, Goodwin ME, Birrer MJ and Chambers TC: The c-Jun $\mathrm{NH}(2)$-terminal protein kinase/AP-1 pathway is required for efficient apoptosis induced by vinblastine. Cancer Res 61: 4450-4458, 2001.

35. Losa JH, Parada Cobo C, Viniegra JG, Sanchez-Arevalo Lobo VJ, Ramon y Cajal S and Sanchez-Prieto R: Role of the p38 MAPK pathway in cisplatin-based therapy. Oncogene 22: 3998-4006, 2003.

36. Olson JM and Hallahan AR: p38 MAP kinase: a convergence point in cancer therapy. Trends Mol Med 10: 125-129, 2004

37. Bulavin DV, Saito S, Hollander MC, Sakaguchi K, Anderson CW, Appella E and Fornace AJ Jr: Phosphorylation of human p53 by p38 kinase coordinates $\mathrm{N}$-terminal phosphorylation and apoptosis in response to UV radiation. EMBO J 18: 6845-6854, 1999.

38. Weldon CB, Parker AP, Patten D, Elliott S, Tang Y, Frigo DE, Dugan CM, Coakley EL, Butler NN, Clayton JL, Alam J, Curiel TJ, Beckman BS, Jaffe BM and Burow ME: Sensitization of apoptotically-resistant breast carcinoma cells to TNF and TRAIL by inhibition of $\mathrm{p} 38$ mitogen-activated protein kinase signaling. Int J Oncol 24: 1473-1480, 2004.

39. Rengifo-Cam W, Umar S, Sarkar S and Singh P: Antiapoptotic effects of progestin on pancreatic cancer cells are mediated by sustained activation of nuclear factor- $\kappa \mathrm{B}$. Cancer Res 67: 7266-7274, 2007. 